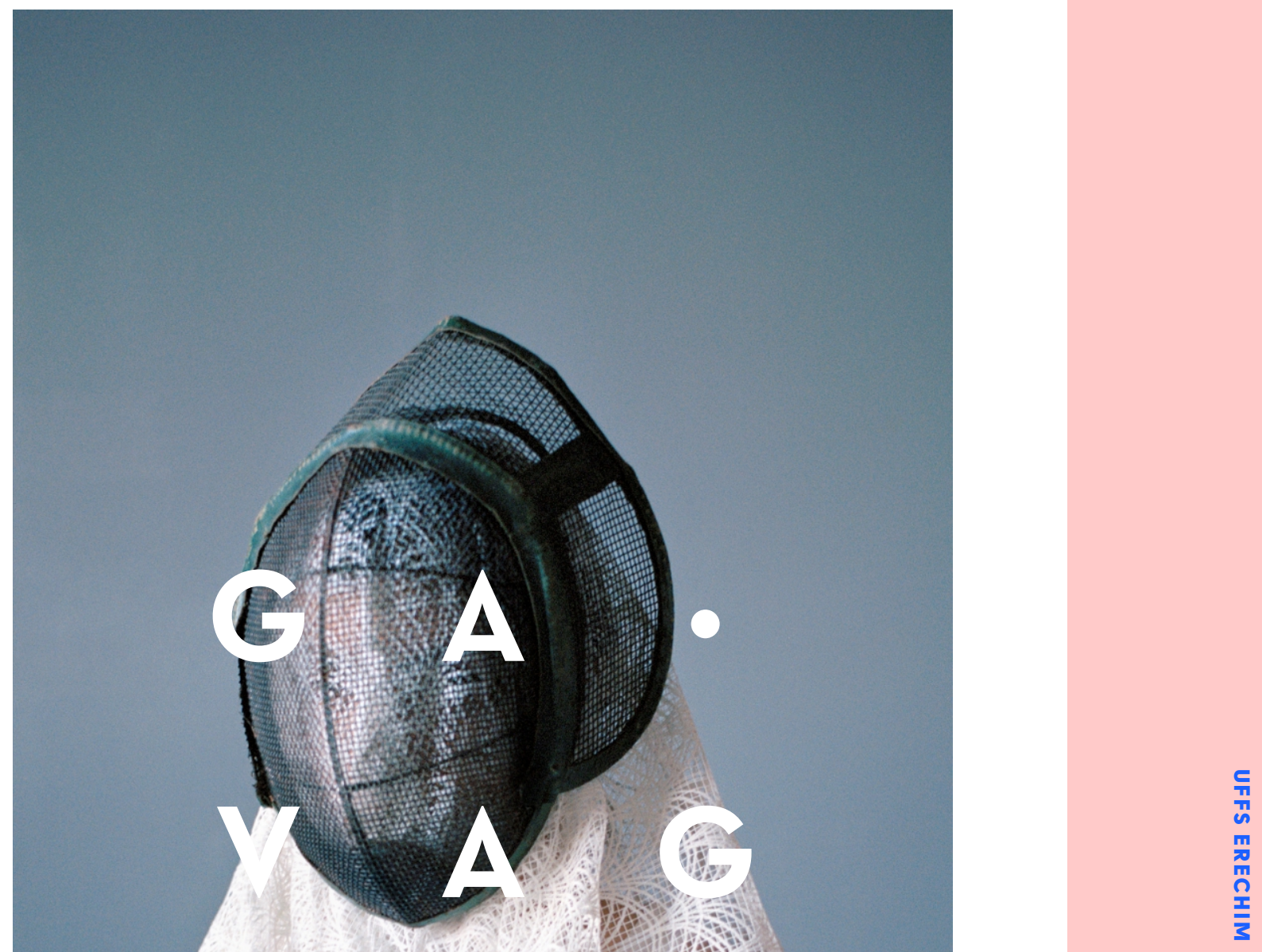


GAVAGAI: REVISTA INTERDISCIPLINAR DE HUMANIDADES

GRUPO DE TRABALHO DO MESTRADO DE CIÊNCIAS HUMANAS

UNIVERSIDADE FEDERAL DA FRONTEIRA SUL, CAMPUS ERECHIM

ENDEREÇO PARA CORRESPONDÊNCIA / DIRECCIÓN POSTAL / MAILING ADDRESS UNIVERSIDADE FEDERAL DA FRONTEIRA SUL, CAMPUS ERECHIM

GAVAGAI - REVISTA INTERDISCIPLINAR DE HUMANIDADES

AV. DOM JOĀO HOFFMANN, 313 ,

BAIRRO FÁTIMA, JUNTO AO SEMINÁRIO NOSSA SENHORA DE FÁTIMA

ERECHIM / RS . CEP 99700.000

FONE: (54) 3321-7050

E-MAIL: GAVAGAI@GAVAGAI.COM.BR

IMAGENS: CAPA / ARTIGOS • SÉRIE HERITAGE • MARIE HUDELOT

ISSN 23580666

DADOS INTERNACIONAIS DE CATALOGAÇĀO NA PUBLICAÇĀO (CIP)

Gavagai: Revista Interdisciplinar de Humanidades/Universidade Federal da Fronteira Sul - Campus Erechim. - Vol. I, n. I (mar./abr. 2014). - Erechim: [s.n.], 2014.

Semestral

1. Periódico. 2. Interdisciplinar. 3. Ciências Humanas.

4. Humanidades. I. Universidade Federal da Fronteira Sul.

Il. Título.

CDD: 300 


$$
\begin{array}{ccc}
\text { - } & \mathbf{G} & \mathbf{A} \\
\mathbf{V} & \bullet & \mathbf{A} \\
\mathbf{G} & \mathbf{A} & \mathbf{I}
\end{array}
$$


EDITOR-CHEFE / EDITOR JEFE / EDITOR-IN-CHIEF

UNIVERSIDADEFEDERAL DESANTA CATARINA (UFSC)

EDITORES EXECUTIVOS / EDITORES EJECUTIVOS / EXECUTIVE

EDITORS

ANI CARLA MARCHESAN

UNIVERSIDADEFEDERAL DAFRONTEIRA SUL, CAMPUS CHAPECÓ (UFFS)

CASSIOBRANCALEONE

UNIVERSIDADEFEDERAL DAFRONTEIRA SUL, CAMPUS ERECHIM (UFFS)

FÁBIO FRANCISCO FELTRIN DE SOUZA

UNIVERSIDADEFEDERAL DA FRONTEIRA SUL, CAMPUS ERECHIM (UFFS)

JERZY ANDRÉ BRZOZOWSKI

UNIVERSIDADEFEDERAL DA FRONTEIRA SUL, CAMPUS ERECHIM (UFFS)

ROBERTO CARLOS RIBEIRO

UNIVERSIDADEFEDERAL DAFRONTEIRA SUL, CAMPUS ERECHIM（UFFS）

ROBERTORAFAEL DIAS DA SILVA

UNIVERSIDADEFEDERAL DAFRONTEIRA SUL, CAMPUS ERECHIM (UFFS) 


\section{CONSELHO EDITORIAL}

- armando chaguaceda - uniVersidad VERACRUZANa (MÉXICO) - BIANCA SALAZAR GUIZZO

. UNIVERSIDADE LUTERANA DO BRASIL (ULBRA) CARLA SOARES - PONTIFICIA UNIVERSIDADE CATÓlICA (PUC-RJ) DANIELA MARZOLA FIALHO - UNIVERSIDAdE FEDERAL DO RIO GRANDE DO SUL (UFRGS) • DÉCIO RIGATTI - UNIVERSIDADE FEDERAL DO RIO GRANDE DO SUL (UFRGS)/ UNIRITTER - DURVAL MUNIZ ALBUQUERQUE JUNIOR - UNIVERSIDAde FEDERALO RIO GRANDE DO NORTE (UFRN). ELIANA DE BARROS MONTEIRO - UNIVERSIDADE FEDERAL DO VALE DO SÃO FRANCISCO (UNIVASF) - ELIO TRUSIAN - UNIVERSITÀ DEGLI STUDI DI ROMA LA SAPIENZA (ITÁLIA) - FÁBIO LUIS LOPES DA SILVA - UNIVERSIDADE FEDERAL DE SANTA CATARINA (UFSC) - FELIPE S. KARASEK - INSTITUTO de DESENVOLVIMENTO CULTURAL (IDC) •

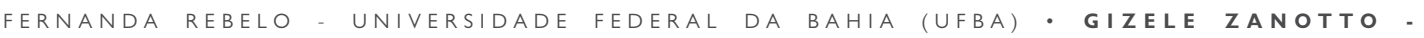
UNIVERSIDADE DE PASSO FUNDO (UPF) • JOSÉ ALVES DE FREITAS NETO - UNIVERSIDADE DE CAMPINAS (UNICAMP) - KANAVILLIL RAJAGOPALAN - UNIVERSIDADE DE CAMPINAS (UNICAMP) - MARGARETH RAGO - UNIVERSIDADE DE CAMPINAS (UNICAMP) - MARIA ANTONIA DE SOUZA - UNIVERSIDADE ESTADUAL DE PONTA GROSSA (UEPG)/ UNIVERSIDADE TUIUTI DO PARANÁ (UTP) - MARIA BERNADETE RAMOS FLORES - UNIVERSIDADE FEDERAL DE SANTA CATARINA

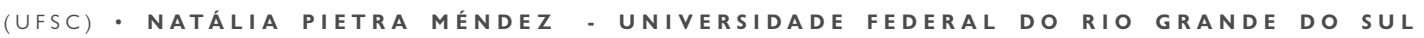
(UFRGS) - NELSON G. GOMES - UNIVERSIDADE DE bRASÍlIA (UNB) - PATRíCIA gRACIELA DA ROCHA - UNIVERSIDADE FEDERAL DO MATO GROSSO DO SUL (UFMS) - PATRICIA MOURA PINHO - UNIVERSIDADE FEDERAL DO PAMPA (UNIPAMPA) - PAULA CORREA HENNING UNIVERSIDADE FEDERAL DO RIO GRANDE (FURG) P PEDRO DE SOUZA - UNIVERSIDADE FEDERAL DE SANTA CATARINA (UFSC) - RAFAEL JOSÉ DOS SANTOS - UNIVERSIDADE DE CAXIAS DO SUL (UCS) - RAfael werner lopes - instituto de desenvolvimento cultural (IDC) • Raul ANTELO - UNIVERSIDADE FEDERAL DE SANTA CATARINA (UFSC) - RICARDO ANDRÉ MARTINS UNIVERSIDADE ESTADUAL DO CENTRO-OESTE (UNICENTRO) - ROBERTO MACHADO UNIVERSIDADE FEDERAL DO RIO DE JANEIRO (UFRJ) - RODRIGO SANTOS DE OLIVEIRAUNIVERSIDADE FEDERAL DO RIO GRANDE (FURG) • ROSÂNGELA PEDRALL - UNIVERIDADE FEDERAL DE SANTA CATARINA (UFSC) - SUZANA G. ALBORNOZ - UNIVERSIDADE FEDERAL DO RIO GRANDE (FURG) - VIVIANE CASTRO CAMOZZATO - UNIVERIDADE ESTADUAL DO RIO GRANDE DO SUL (UERGS). 


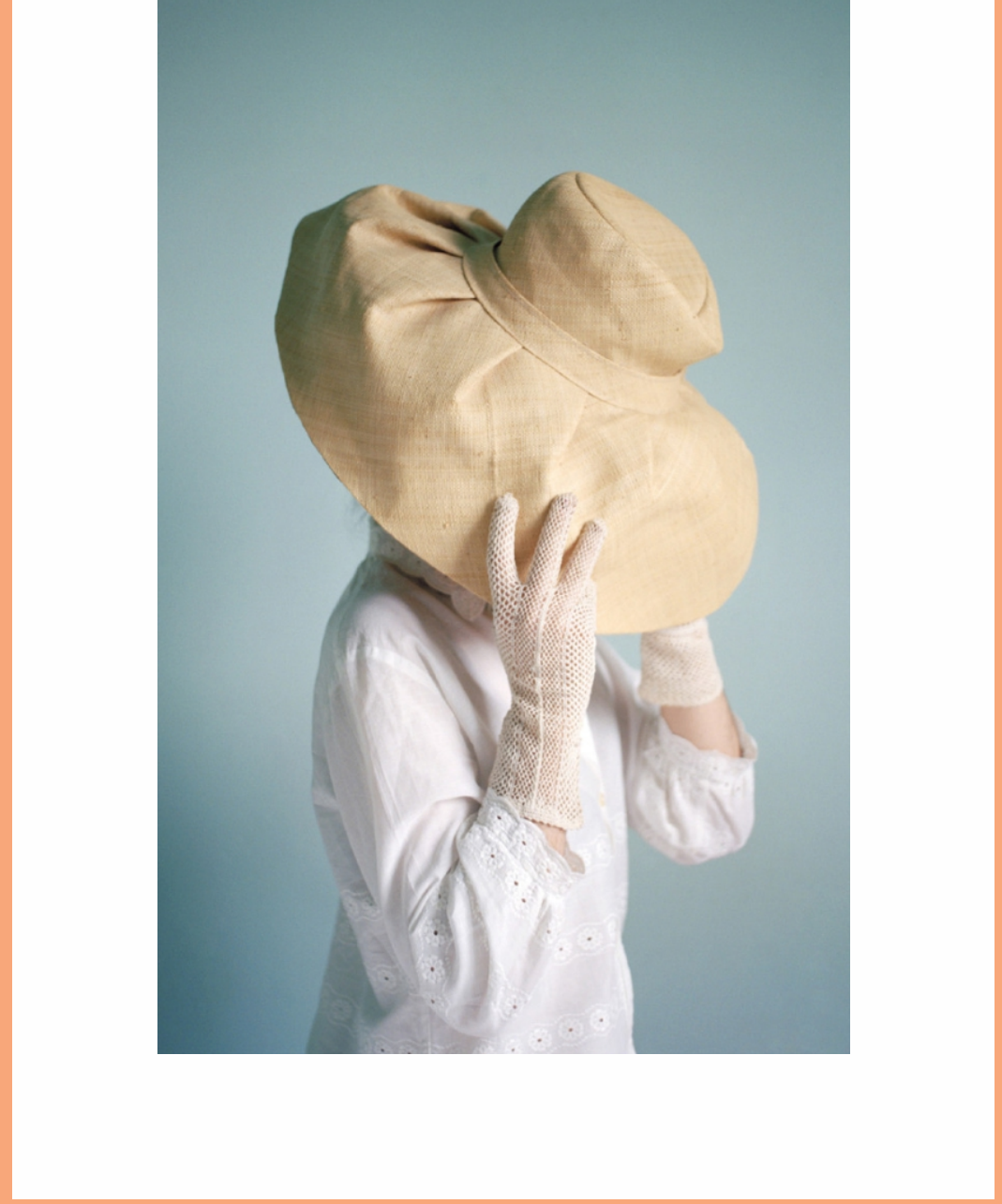

\title{
NEURATH E H.G. WELLS: EM DIREÇÃO A UMA CIÊNCIA SOCIAL UTÓPICA
}

\begin{abstract}
Resumo: Este artigo discute o conceito de utopia presente na obra de Otto Neurath em relação à noção literária de utopia, particularmente aquela encontrada nos textos de H.G. Wells. A posição de Neurath recupera o estilo dos socialistas utópicos, que faziam propostas científicas de melhorias sociais em meio a peças literárias. Neurath propõe uma ciência social que tem como objetivo criar utopias. Este artigo mostra a continuidade de tais propostas com as ideias que aparecem na obra de Wells, enfatizando a noção de concepção de mundo científica, proposta por Neurath e pelo Círculo de Viena, e incorporada ao Movimento pela Unidade da Ciência. A concepção de uma ciência social utópica contribui para uma sociedade cientificamente educada, capaz de discutir democraticamente as supostas melhorias que lhe sejam apresentadas.
\end{abstract}

Palavras-chave: Círculo de Viena. Filosofia da ciência. Ficção científica. Utopia. 


\section{INTRODUÇÃO}

Marx e Engels criticaram, em meados do século XIX, a presença do pensamento utópico no socialismo. Eles procuraram resolver os problemas da sociedade por meio da utilização de um instrumental teórico científico, criando uma ciência do socialismo - a ciência social marxista. O socialismo anterior ao marxismo era utópico, por imaginar arranjos sociais ideais, em analogia ao livro Utopia de Thomas More, mas sem partir de uma compreensão científica sobre o funcionamento da sociedade e da economia. O socialismo utópico seria, dessa forma, "sonhador", "fora da realidade" ou "ingênuo" por propor a implantação das condições sociais ideais em um acordo entre as diferentes classes sociais, sem uma revolução. Do ponto de vista marxista, o socialismo utópico estava fadado ao fracasso, por ignorar a necessidade da luta de classes, constatada pela ciência social marxista (MARX; ENGELS, 1848; ENGELS, 1880).

Quando voltamos nossas atenções ao período entre guerras do século XX, notamos uma situação interessante. Por um lado, a crítica marxista ao pensamento utópico atingia sua maturidade na obra de Karl Mannheim, que notava o desaparecimento das utopias como consequência do processo de atacar as ideologias e propunha uma reforma no marxismo: a ciência social deveria ser capaz de identificar melhor as utopias, distinguindo-as das ideologias (MANNHEIM, 1936). Por outro lado, na arte, a ideia de que a ciência pode fundamentar, planejar e reger uma sociedade ideal recebia ataques ferozes: autores como o britânico Aldous Huxley (1932) e o soviético Yevgeny Zamyatin (1924) mostraram em seus romances distópicos que o cientificismo no planejamento social pode levar a consequências desastrosas.

O objetivo deste texto é apresentar algumas propostas de Otto Neurath, pensador austríaco desse período. Neurath era integrante do Círculo de Viena, grupo interdisciplinar de intelectuais que refletiam sobre a ciência. Veremos que ele propôs uma maneira de conceber a ciência, particularmente a ciência social, na qual utopias e distopias desempenham um papel importante no planejamento social. Encontraremos ponto de vista semelhante na ficção científica do britânico H.G. Wells. A partir da filosofia da ciência de Neurath, mostraremos uma possibilidade de reintegração da utopia artística nas ciências sociais.

\section{NEURATH E A CIÊNCIA DAS UTOPIAS}

Em um artigo de 1920-21, Neurath descreve uma situação terrível na Alemanha pós-guerra, onde ocorria guerra civil, fome, doença e assassinato; e a única maneira de superar isso, diz ele, é por meio da nossa vontade e do nosso conhecimento. Nessa situação, continua ele, "os marxistas mataram o utopianismo divertido, salvando assim a unidade do partido e o 'rigor científico', mas também paralisando o ímpeto de inventar novas formas" (NEURATH, 1920-21, p. 345). Neurath se refere àquilo que Mannheim notaria alguns anos depois: a crítica ao socialismo utópico, feita pelos marxistas, acabou por reprimir o movimento artístico de pensar no mundo ideal.

A atuação dos cientistas sociais, de acordo com Neurath, deve ser guiada por um plano geral: não basta tomar certas medidas, como, por exemplo, um decreto tecnocrático determinando a abolição da propriedade privada, sem que uma reorganização geral da sociedade não fosse planejada e estabelecida. Qualquer plano político, qualquer "revolução comunista", feito sem um planejamento que atendesse às demandas das diferentes classes sociais presentes na comunidade, seria uma perda de tempo, pois só agravaria a situação da luta de classes (NEURATH, 1920-21, p. 347-8).

Neurath, dessa forma, se mostra descontente com o marxismo. E isso vem de uma experiência política que ele tinha tido. Com o final da primeira guerra mundial, o governo social democrata, que havia derrubado a monarquia na Bavária, encarregou Neurath de um escritório de planejamento da reconstrução daquele que se tornava um estado da Alemanha. Durante alguns meses, Neurath conseguiu encontrar justas medidas entre os interesses econômicos e sociais das diferentes classes sociais daquele lugar, como industriais, mineiros, agricultores, comerciantes etc. - tanto patrões quanto trabalhadores. Houve, em 1919, uma revolução comunista na Bavária e a instauração da chamada República Soviética de Munique. O trabalho de Neurath era admirado pelos revolucionários, que lhe permitiram continuar. Até que o governo central alemão reprimiu violentamente a revolução. Neurath foi preso, deportado de volta à Áustria e proibido de entrar na Alemanha durante sete anos. O que Neurath aprendeu com essa experiência é que o processo de estabelecer o socialismo não deve envolver a abolição autoritária da propriedade privada, pois isso cria muitos inimigos que acabam excluídos do objetivo maior de criar uma sociedade justa. Assim, ele se posiciona contra a ideia de que somente a revolução pode superar o conflito entre as classes sociais: devemos preferir outro caminho para atingir a justiça social (cf. NEURATH; COHEN, 1973 ; cf. CARTWRIGHT et al., 1996).

Desse modo, no início dos anos 1920, a proposta de Neurath é para que a ciência social faça um trabalho de comparação entre as ordens sociais existentes, historicamente dadas, e as utopias, os arranjos sociais imaginados. A sociedade ideal, para Neurath, não será encontrada como uma consequência das leis históricas, mas deve ser produzida por um esforço criativo. Diz Neurath que a social democracia deve avançar do "historicismo, que tornou o movimento forte e poderoso no passado, em direção ao utopianismo, que sinaliza uma nova era de formatação consciente do futuro, com o conhecimento das necessidades históricas" 
(NEURATH, 1920-21, p. 370; cf. NEURATH, 1919a).

Em um texto de 1919, Neurath apresenta uma imagem interessante. Ele afirma que a palavra "utopista" é frequentemente usada com um tom desdenhoso, uma maneira de julgar pessoas que "procuraram dar uma olhada atrás das cortinas do palco do destino, e que se esforçaram para preparar a peça do futuro". Neurath continua, dizendo que "agora as cortinas se abrem, e os atores saem das coxias, tímidos e desajeitados [...]. Uns tentam fingir espontaneidade, outros se voltam ao ponto ${ }^{1}$ e escutam aliviados o texto que vem dali". A imagem é a de atores que estão em um palco e não sabem o que têm que fazer, não sabem como proceder numa peça que não foi planejada ou ensaiada; e, então, Neurath põe em cena os economistas e sociólogos de sua época: "Rathenau, Atlanticus, Popper-Lynkeus e outros são de repente não mais 'utopistas', mas tecnólogos sociais² que avançaram adiante de seu tempo. De todos os cantos", continua Neurath, "ecoam slogans e demandas, como os que encontramos em Fourier, Cabet, Bellamy, bem como em Thomas More ou Platão" (NEURATH, 1919b, p. 137). Com isso, Neurath aproxima os cientistas sociais de sua época dos socialistas anteriores a Marx, chamados pejorativamente de utópicos, e dos autores clássicos de utopias. Na sequência do texto, Neurath diz que a ciência social negligencia as utopias, o que é indevido: as utopias são os únicos experimentos de tecnologia social disponíveis, e a ciência social deveria tratá-las de maneira condizente.

Notamos que Neurath propõe que a ciência social retome o objetivo característico do socialismo utópico, de imaginar arranjos sociais ideais. O cientista social deve criar utopias, como fizeram Platão e Thomas More, assim como os socialistas utópicos anteriores ao marxismo, como Cabet, Bellamy e Fourier. Uma estratégia comum entre esses autores é a de elaborar uma peça literária, contar uma história em que viajantes visitam um lugar onde a sociedade está organizada de uma maneira supostamente ideal. Com isso, eles pretendem criticar a ordem social existente e fomentar a transformação social entre seus leitores.

Porém, Mannheim não consideraria esse tipo de obra como utopia, mas como ideologia. Segundo ele, a literatura utópica, por si só, não apresenta o caráter de "ideias transcendentes da situação [...] que, de alguma forma, têm um efeito transformador da ordem sócio-histórica existente". As utopias literárias, como outras peças artísticas, contos de fadas, mitos e promessas religiosas, não conclamam à transformação social, à revolução, e, dessa forma,

1 Em alemão: "Souffleurkasten", literalmente a caixa do soprador. Tal prática, em desuso no teatro brasileiro, mas comum em alguns lugares da Europa, consiste em esconder um contrarregra em um lugar estratégico para "soprar" o texto aos atores mais esquecidos.

2 Em alemão: "Gesellschaftstechniker", termo geralmente traduzido como "engenheiro social". Preferimos o termo "tecnólogo" a "engenheiro", devido ao valores negativos, tecnocratas, comumente associados à engenharia social, que não aparecem na proposta de Neurath (1919a). Cf. Cunha (2013) para mais comentários. são "mais propriamente cores complementares na imagem da realidade existente no momento do que utopias trabalhando em oposição ao status quo e desintegrando-o" (MANNHEIM, 1936, p. 205). Para Mannheim, desse modo, a arte de imaginar um mundo melhor é uma expressão de um desejo da sociedade, mas não necessariamente a indicação de um caminho para a transformação social, pois não se insere em um contexto de luta de classes, não conduz de maneira efetiva à revolução. As utopias literárias acabariam mantendo as pessoas sob controle, sonhando com um mundo melhor, mas sem fazer coisa alguma para transformar a realidade em que vivem. Em suma, a arte utópica, para Mannheim, recai nos erros do socialismo utópico, ignorando as leis dialéticas que regem a história e o desenvolvimento das sociedades.

Em 1930, Neurath publicou uma resenha do livro de Mannheim. ${ }^{3}$ Em tal texto, Neurath elogia a ciência social marxista por adotar o materialismo, posição que se afasta de doutrinas metafísicas. Mas, ele critica a pretensão da ciência social reformada, proposta por Mannheim, de tentar se afastar da unilateralidade e da falibilidade típicas da ciência; ao invés de tal ciência assumir e tentar lidar com tais problemas, ela permanece presa à noção de luta de classes e a questões partidárias (NEURATH, 1930). A proposta de Neurath para a ciência social, assim, é para que seja abrandada a presença do referencial teórico marxista e para que não se leve tão a sério a luta de classes e o determinismo histórico. Além disso, Neurath defende que os cientistas sociais devem voltar ao trabalho criativo de imaginar utopias.

\section{O Cí́RCULO DE VIENA E A CONCEPÇÃO DE MUNDO CIENTÍFICA}

Para compreender melhor essa proposta, devemos lembrar que Neurath se uniu ao grupo de pensadores conhecido como Círculo de Viena em meados da década de 1920, enquanto trabalhava na reformulação urbana de Viena (CARTWRIGHT et al., 1996; VOSSOUGHIAN, 2011). Tal grupo, como expresso no manifesto Wissenschaftliche Weltauffassung (1929), era voltado a estudar a ciência como uma concepção de mundo, como uma atitude fundamental ou uma orientação de pesquisa, que rejeita distâncias escuras, profundezas insondáveis e enigmas insolúveis; "na ciência não há profundezas; há superfície em toda parte" (HAHN; NEURATH; CARNAP, 1929, p. 86-7). A ciência, na visão de tal grupo, é o ponto de vista oposto a uma visão mística do mundo, que considera que há mistérios incognoscíveis, que há perguntas sem resposta e que devemos nos resignar diante de certos problemas ou esperar alguma solução divina, completa e definitiva a certas questões. Para o Círculo deViena, cabe somente

\footnotetext{
3 Neurath trata do texto que trabalhamos aqui, publicado em 1929; a edição que usamos, de 1936, é uma versão ampliada que contém o texto comentado por Neurath.
} 
a nós, os seres humanos, resolver nossos problemas por meio do trabalho.

O objetivo do Círculo de Viena era promover a ciência unificada por meio da interação e do esforço coletivo de todos aqueles que adotam a concepção de mundo científica em seus trabalhos e na vida. Com isso, seria estabelecida uma oposição ao obscurantismo, que se manifestava na tendência metafisica e teológica da filosofia daquela época (HAHN; NEURATH; CARNAP, 1929, p. 867). O problema, como ficaria claro alguns anos mais tarde, é que governos totalitários viriam a se apropriar de tal obscurantismo para apresentar medidas políticas como se fossem inquestionáveis, como soluções finais e definitivas aos problemas da sociedade. Ao longo dos anos 1930, Neurath, junto ao Círculo de Viena, organizou o Movimento pela Ciência Unificada, que propunha a elaboração de uma enciclopédia para apresentar a pluralidade característica da ciência (NEURATH, 1935; 1936); a produção de tal obra aproximaria os adeptos da concepção de mundo científica, e a obra produzida serviria para divulgar uma imagem adequada da ciência. Essa proposta pode ser vista como uma utopia: a de uma sociedade composta por pessoas que adotam a concepção de mundo científica, que se comunicam livremente e que cooperam pela compreensão da ciência e pela melhoria da educação e da sociedade (NEMETH, 1982b).

\section{A International Encyclopedia of Unified Science (NEURATH;} CARNAP; MORRIS, 1955; 1970) acabou sendo publicada a partir de 1938 nos Estados Unidos, depois de o projeto ter sofrido perseguições na Europa (SOULEZ, 2005; MARION, 2005). O número de abertura de tal obra contou com a participação de Neurath e Carnap, integrantes já exilados do Círculo de Viena, além dos pragmatistas americanos John Dewey e Charles Morris, do cientista Niels Bohr e de Bertrand Russell. A imagem da ciência gerada pela enciclopédia, como Neurath explica em seu capítulo do número de abertura, é a de que a ciência se unifica em um mosaico, uma figura formada por peças irregulares e que aparentemente não se encaixam, resultado do esforço coletivo de uma comunidade; isso é posto em oposição à imagem de um sistema, em que todas as partes são uniformes e se encaixam perfeitamente por um método único - como nos sistemas metafísicos e teológicos contra os quais o Círculo de Viena e os enciclopedistas queriam lutar (NEURATH, 1938; NEMETH; ROUDET, 2005; NEMETH; STADLER, 1996).

Uma população cientificamente educada - conforme essa compreensão da ciência - não se deixaria levar pela ideia de um governo com poderes absolutos que apresentasse soluções completas e definitivas aos problemas: alguém que adota a concepção de mundo científica sabe que um problema só pode ser resolvido por meio de muito esforço, passo a passo, com tentativa e erro; sabe que nenhuma solução é universalmente válida e absolutamente correta, o melhor que podemos ter é um esforço constante para melhorar o mundo à nossa volta. Notamos, assim, o caráter democrático da ciência para Neurath e para o Círculo de Viena: a ciência deve ser produzida e divulgada para o maior número possível de pessoas, em um ambiente livre. O famoso projeto da linguagem fisicalista do Círculo de Viena pode ser compreendido nesses termos: formular os enunciados da ciência com a clareza das construções lógicas seria um passo importante para a disseminação científica (NEURATH, 1937).

Nessa concepção, a ciência é um empreendimento plural, por envolver contribuições dos mais diversos tipos, sobre variados assuntos, formando um mosaico; é também marcada pelo falibilismo, pela possibilidade de erro e de constante revisão e reconstrução dos conhecimentos adquiridos. Esses dois aspectos aparecem na famosa metáfora do barco, elaborada por Neurath:

\begin{abstract}
Imagine marinheiros que, longe no mar, modificam sua embarcação desajeitada de uma forma mais circular para uma em formato de peixe. Eles utilizam madeira encontrada à deriva além da madeira da velha estrutura, para modificar o esqueleto e o casco da embarcação. Mas eles não podem aportar para começar do rascunho. Durante o trabalho, eles permanecem na velha estrutura e lidam com pesadas ventanias e ondas trovejantes. Ao transformar seu barco, eles cuidam para que não ocorram vazamentos perigosos. Um novo barco cresce a partir do velho, passo a passo - e enquanto ainda estão construindo, os marinheiros podem já estar pensando em uma nova estrutura, e eles não vão concordar sempre um com o outro. A tarefa toda continuará de uma maneira que não podemos sequer antecipar hoje (NEURATH, 1944, p. 47).
\end{abstract}

Ou seja, não podemos deixar de seguir navegando para produzir o barco perfeito, não podemos deixar de lado nossas vidas para construir o mundo ideal. E nunca conseguiremos construir o mundo ideal da maneira perfeita como imaginamos, porque não temos os componentes ideais, apenas as coisas que encontramos enquanto navegamos. Muitas vezes nossa construção sequer pode seguir o rumo que gostaríamos que seguisse, porque sofremos frequentemente com tempestades. E nossa ideia do barco perfeito, ou do mundo ideal, muda o tempo todo, em uma construção coletiva e plural.

Voltando ao tema das ciências sociais e da crítica ao marxismo de Mannheim, podemos dizer que Neurath nota que é o momento de fazer uma grande reforma no barco: o casco fornecido pelo marxismo pode ter nos ajudado até aqui e pode fornecer o material para construir um novo casco. Mas não devemos nos esquecer de construir estruturas que nos ajudem a guiar o barco em meio às ventanias e ondas trovejantes; nesse processo, propõe Neurath, os cientistas sociais devem retomar a criatividade das utopias. Mostramos que Neurath cita socialistas utópicos, além de 
Platão e de Thomas More, como exemplos desse tipo de criação. Mas a menção que nos interessa aqui é a que apareceu no número de abertura da enciclopédia: ali, Neurath diz que a concepção de mundo científica é plural, apresentando várias formas, não se manifestando apenas em trabalhos científicos propriamente ditos, mas também na filosofia e na arte. A obra Der logische Aufbau der Welt, de Carnap, seu colega no Círculo de Viena, é o exemplo de filosofia produzida com uma atitude científica; e "a ficção científica de H.G. Wells” é o exemplo na arte (NEURATH, 1938, p. 12-3).

Vejamos, então, alguns exemplos da tradição literária de escrever utopias, a tradição que nos trouxe a ficção científica de H.G.Wells, para compreender essa afirmação de Neurath e a recomendação que ele faz à ciência social.

\section{UTOPIAS ARTÍSTICAS E H.G. WELLS}

O termo 'utopia' foi criado por Thomas More no século XVI em um contexto de crítica social. No entanto, o estilo literário que ele nomeou já existia desde a Antiguidade. Trata-se de uma história em que um viajante vai a um lugar desconhecido e ali fica conhecendo outra forma de organização social, que permite que ele desenvolva uma crítica a certos aspectos de seu lugar de origem, além de propor projetos para o futuro (VIEIRA, 2010; ALDRIDGE, 1984). Essa é a ideia básica da República de Platão e também da Cidade de Deus de Agostinho, embora em tais livros não haja uma viagem propriamente dita (BERNERI, 1950). No livro de More, um navegador português conta sua história ao narrador do livro, apresentando um relato de suas aventuras com um grupo de viajantes que foi até o Atlântico sul e aportou em uma ilha chamada Utopia. Ele encontrou uma sociedade organizada de uma maneira que ele considera perfeita ou, ao menos, melhor que a da Europa; é importante ressaltar que o narrador do livro - o personagem que representa More - considera que algumas daquelas coisas são absurdas, mas que outras são desejáveis (MORE, 1516). ${ }^{+}$

More traz algumas críticas e discussões interessantes para a sociedade de sua época; por exemplo, as pessoas na ilha de Utopia não prezam metais e pedras raras, coisas consideradas preciosas na Europa na época de More e até hoje no mundo todo. A economia utopiana é baseada em espécie, sem moeda; e os utopianos consideram que pedras e metais brilhantes são brinquedos para as crianças, e veem os que se adornam assim como infantilizados. Um trecho que mostra isso é quando a ilha de Utopia recebe a visita de embaixadores estrangeiros que chegam enfeitados com pérolas,

4 Existem controvérsias sobre a opinião de More a respeito da ordem social descrita (BERNERI, 1950; DAVIS, 2010). correntes de ouro e pedras. A população vê isso como vergonhoso, e algumas crianças ficam perplexas - ao que a mãe delas responde que aqueles devem ser os bobos da corte vizinha (MORE, 1516). Com isso, More apresenta uma crítica à economia e aos costumes de ostentação que surgem da desigualdade social.

Em Utopia, há algumas peculiaridades sobre o casamento. Quando um homem e uma mulher decidem se casar, eles devem ser inspecionados um pelo outro em plena nudez sob a supervisão de um padrinho ou madrinha. A questão é que as pessoas na Europa da época faziam inspeções minuciosas em cavalos que iriam comprar, mas se comprometiam pelo resto da vida com uma pessoa de quem viram apenas o rosto. O casamento para os utopianos é uma questão civil muito séria, embora haja na ilha religiões bem fundamentadas e a garantia da liberdade religiosa. Há, dessa forma, a possibilidade do divórcio em casos de comum acordo (MORE, 1516). Isso é significativo quando pensamos que na época do livro, um ano antes da reforma de Lutero, More era um diplomata a serviço da Inglaterra governada por Henrique VIII. Alguns anos mais tarde, tal monarca se tornaria o fundador da Igreja Anglicana, depois de ter tido problemas com a Igreja Católica por, entre outras coisas, querer seu próprio divórcio. Embora More tenha sido um opositor do rompimento de Henrique VIII com a Igreja Católica, ele tinha noção de que aqueles temas eram assunto entre seus leitores.

A Utopia de More não traz indicações sobre como produzir aquela sociedade perfeita. Fica subentendido que se trata de uma questão de mudar o sistema de produção e os costumes sociais, reformando o código de leis, a educação, o sistema político e o estilo de vida das pessoas. Não há o chamado para a revolução que Mannheim espera de uma utopia - sequer sabemos se More defendia algo assim. O que temos é a imagem de uma sociedade que não tem os problemas do mundo real, um esforço de pensar em soluções criativas para questões que estão em debate.

Outra utopia importante em nosso contexto é Nova Atlantis de Francis Bacon, escrita um século depois daquela de More. Tal obra é menos voltada a questões de Estado e apresenta soluções imaginativas para problemas da ciência. A estrutura da história é parecida: um grupo de navegadores se perde no Oceano Pacífico e acaba encontrando uma ilha, onde há uma civilização organizada de maneira perfeita aos olhos do narrador. $\mathrm{O}$ aspecto interessante de tal lugar é que lá a ciência é amplamente incentivada e organizada institucionalmente, mesmo sendo a sociedade religiosa em larga medida: a natureza é obra de Deus e a ciência é a graça divina de conhecer tal obra (BACON, 1627). Com esse texto, Bacon chama a atenção para a necessidade do incentivo, do financiamento e da institucionalização da ciência; e, para isso, mostra uma civilização extremamente avançada que conseguiu tudo o que tem a partir da pesquisa científica. 
Em Bensalem, a cidade onde os náufragos de Bacon recebem abrigo, há a Casa de Salomão: uma mistura de mosteiro, universidade e laboratório de pesquisas, com um hospital vinculado. Tal instituição é organizada em departamentos, já com a ideia de que deve haver a especialização dos cientistas em áreas específicas. A Casa de Salomão organiza expedições periódicas a outros lugares, mesmo à Europa, onde os pesquisadores permanecem incógnitos e adquirem todo tipo de conhecimento de maneira sistemática. Assim, eles possuem todo o conhecimento disponível à sociedade de Bacon e mais os seus próprios avanços (BACON, 1627; BERNERI, 1950). As inovações científicas e tecnológicas descritas por Bacon são extrapolações da ciência de sua época, tais como a cura de diversas doenças e mecanismos que imitam o movimento de animais; há também laboratórios onde fenômenos meteorológicos são reproduzidos e estudados; terrários, viveiros e um centro de pesquisa em matemática (BACON, 1627).

O objetivo de Nova Atlantis é bem claro: gerar em seus leitores a ideia de que a ciência poderia ser bem organizada e financiada e que isso traria benefícios gerais. Isso é mais fácil de ser atingido, já que, em tese, bastaria que uma instituição como a Casa de Salomão fosse criada - um centro de pesquisas como os que temos atualmente. ${ }^{5}$ De fato, a Royal Society, instituição inglesa de fomento científico, foi fundada naquele mesmo século a partir do modelo proposto por Bacon. $\mathrm{O}$ aspecto social que Bacon critica em Nova Atlantis é o fato de que a ciência e a religião eram vistos como opostos, e o Estado, de modo a evitar problemas com o clero, restringia investimentos em pesquisa científica. O livro de Bacon indica maneiras de atingir uma justa medida entre os dois extremos, garantindo o financiamento da ciência e vendendo a ideia com promessas de melhorias sociais, como o avanço da medicina que viria com um hospital-escola.

$\mathrm{O}$ incentivo à pesquisa científica e o desejo de que a ciência se tornasse mais presente na sociedade eram também objetivos da utopia da ciência unificada de Neurath. No entanto, a ciência e a sociedade que Bacon descreve em Nova Atlantis não são muito compatíveis com as propostas neurathianas. Bacon considera que o conhecimento obtido pela Casa de Salomão é estável, seguro e definitivo - e que deve ser mantido em regime de segredo de Estado. Como sabemos, Neurath via os cientistas como navegando em mar aberto a bordo de um barco que precisa ser reconstruído com o material que têm à mão, sem poder chegar a um conhecimento seguro e infalível. Além disso, o conhecimento científico, para Neurath, deve ser democrático, sendo produzido com a participação de todos os envolvidos, de todos os marinheiros do barco. Esse tipo de coisa aparece em algumas utopias do início do século XX, propostas justamente pelo autor que Neurath considerou exemplar no uso da atitude científica para fazer arte,

5 Berneri (1950) aponta que vivemos hoje em uma Casa de Salomão e que, como Bacon, estamos deslumbrados com os avanços da ciência.
H.G. Wells.

Wells começou a publicar seus livros no final do século XIX. Tal século, como dissemos, viu a passagem do socialismo utópico para o socialismo científico. De fato, a literatura utópica passou por grandes alterações nesse período, sendo que a principal delas é a preponderância do pessimismo, seguindo a tendência filosófica e artística daquele século, como encontramos em autores como Dostoiévski e Nietzsche (KATEB, 1968). Surgem, assim, as chamadas distopias, obras que, ao invés de mostrar uma sociedade perfeita, como nas utopias, apresentam os maiores horrores que podemos imaginar - geralmente resultados de tentativas malsucedidas de aplicar um ideal de sociedade perfeita (ALDRIDGE, 1984).6 A obra mais famosa de H.G. Wells pode ser caracterizada desse jeito: em The Time Machine, de 1895, o personagem principal viaja no tempo e presencia o futuro terrível reservado à humanidade.

No início de A Modern Utopia, Wells explica que a utopia de alguém que vive nos tempos modernos, posteriores a Darwin, não pode mostrar um lugar perfeito: tem que apresentar um mundo em constante mudança, pois já não conseguimos conceber um mundo fixo, ideal e acabado, uma sociedade absolutamente estável, onde todos os problemas foram solucionados. E nem toleraríamos viver em tal situação. $\mathrm{O}$ único tipo de mundo que conseguimos razoavelmente imaginar é aquele que apresenta problemas, tanto naturais, quanto decorrentes da interação humana. A utopia, nesse sentido, mostra um lugar onde tais problemas existem, mas são tratados de maneira efetiva (WELLS, 1905). Assim, Wells escreve sua utopia em diálogo com as utopias do passado, comentando tais obras e gerando um texto que não é puramente imaginativo, mas que também traz elementos de crítica literária e de reflexão filosófica (JAMES, 2012).

Desse modo, a estrutura de A Modern Utopia é metalinguística: o narrador vai imaginando, junto com um interlocutor, como seria um mundo utópico moderno e, de repente, eles estão lá. À medida em que chegam a conclusões sobre como seria tal mundo, as coisas vão acontecendo, como que realizando a imaginação de Wells. Em um trecho do livro, eles explicam sua situação a um utopiano, dizendo que estão ali "por um ato da imaginação,

\footnotetext{
6 'Utopia' vem de termos gregos que significam "lugar nenhum”, não indicando se é um lugar bom ou ruim. Convencionou-se, no entanto, que as utopias mostram visões otimistas, enquanto as distopias trazem perspectivas pessimistas. Como visões otimistas, enquanto as distopias trazem perspectivas pessimistas. Como
veremos, Wells procura romper com essa valoração associada ao termo 'utopia', veremos, Wells procura romper com essa valoração associada ao termo 'utopia',
indicando que descrições de sociedades ideais podem ser otimistas para algumas pessoas e pessimistas para outras. Cf.Vieira (2010, p. 3-7), para etimologia e usos de 'utopia' e derivados. Aldridge (1984) argumenta que a distopia se desenvolveu como um gênero literário distinto.

7 The Time Machine está no centro de uma discussão sobre os limites entre a utopia e a ficção científica: Claeys (2010) não vê tal obra como utópica, apenas como ficção científica, e Fitting (2010) pensa o contrário. Tais autores concordam que Wells moldou o estilo de narrativa distópica do século XX, que atingiu seu auge com Huxley (1932) e Zamyatin (1924); esse papel de Wells é analisado por Aldridge (1984), no capítulo 2. Essa discussão de crítica literária não entra no escopo do presente texto.
} 
uma daquelas operações metafísicas tão dificeis de tornar críveis" (WELLS, 1905, p. 93). O narrador e seu colega, dessa forma, se veem em um planeta igual ao nosso em muitos aspectos, mas que é diferente na organização social e política.

O mote é tentar imaginar um mundo e todas as pessoas que vivem nele sem as "tradições, associações, preconceitos, leis e laços artificiais, e começar de novo". No entanto, continua Wells, “não conseguimos libertar a nós mesmos” (WELLS, 1905, p. 173). Assim, a utopia moderna de Wells é marcada pela sua própria visão de mundo, um preconceito que molda a realidade mesmo que imaginada. Desse modo, o narrador é uma pessoa bastante entusiasmada com tudo o que vê em Utopia; seu colega, pelo contrário, fica aborrecido com tudo aquilo. Temos, assim, que a utopia do narrador é a distopia de seu interlocutor. Um exemplo dessa discordância é quando eles descobrem que não há animais de estimação em Utopia, uma medida para diminuir as doenças entre as pessoas; o narrador acha que esse é um sacrificio justo, mas seu colega fica inconsolável (WELLS, 1905).

Como exemplo das grandes vantagens de Utopia, podemos mencionar os meios de transporte, que são eficientes, rápidos e seguros, o que permite que as pessoas não fiquem restritas geograficamente, podendo morar longe do trabalho. Isso permite também que as pessoas se mudem com frequência, experimentando novas vivências. Com isso, os costumes de um lugar são mais fáceis de assimilar, já que todos estão acostumados com forasteiros. E, sendo assim, o narrador e seu colega não têm, inicialmente, grandes dificuldades de adaptação à Londres utópica (WELLS, 1905). ${ }^{8}$ Em Utopia, diz Wells, a Casa de Salomão é uma realidade, com diversas universidades fazendo pesquisa avançada $\mathrm{e}$ com relatórios de experimentos sendo noticiados com a mesma rapidez que os resultados de esportes em nosso mundo. A pesquisa científica em Utopia é conduzida de maneira intensa, enquanto na Terra, diz Wells, "não a conduzimos! Nós a deixamos acontecer" (WELLS, 1905, p. 46).

A economia de Utopia é marcada por robôs que fazem o trabalho pesado, não havendo escravos e nem trabalhadores inferiores. Um Estado mundial detém toda a produção, sendo cada país responsável por algum setor da administração. O Estado, assim, também estaria sujeito à seleção natural: em cada lugar, sobreviveram as funções que eram mais bem desempenhadas (WELLS, 1905). ${ }^{9}$ Isso não quer dizer que não haja problemas; mas, em Utopia, a ciência lida de maneira eficiente com eles, mesmo aqueles gerados pela

\footnotetext{
8 James (2012) aponta que o avanço do transporte e da comunicação são pontos de partida comuns a muitas das utopias de Wells. A ideia é que tais avanços produzem inevitavelmente grandes mudanças na sociedade, na economia e no estilo de vida das pessoas.

9 Por exemplo, em um momento de humor britânico, Wells mostra que todos os setores de burocracia do Estado mundial ficaram concentrados em Paris e arredores (WELLS, 1905).
}

própria ciência: por exemplo, "o problema geral da economia utopiana é estabelecer as condições para a aplicação eficiente das quantidades crescentes de energia material [...] às necessidades gerais da humanidade" (WELLS, 1905, p. 60).

A utopia moderna, como aponta Wells, também não pode ser unânime. Em certo momento, o narrador e seu colega encontram um utopiano avesso à organização do mundo onde vive. Trata-se de uma espécie de hippie que rejeita o cientificismo e a tecnologia de Utopia, preferindo viver como um andarilho, acampando e vendendo discos de música que ele mesmo produz para ganhar seu sustento. O chamado "apóstolo da natureza" acredita que a civilização e a tecnologia afastam o ser humano de sua vocação natural, que é a de levar uma vida simples na selva. O narrador acha abominável que alguém não goste daquele mundo, ao passo que seu colega aprecia o romantismo do andarilho (WELLS, [1905], capítulo 4).

Tal pessoa é perfeitamente livre para ser contra a ordem social utopiana e para viver da maneira como bem entender, desde que tenha uma fonte de sustento, mas não possui direitos políticos. $\mathrm{Na}$ utopia moderna de Wells, a classe dos Samurai detém o poder, ao lado de uma minoria de representantes de outras classes. As pessoas de tal classe, os Samurai, precisam seguir um código moral estrito - um código razoável, em constante processo de discussão, revisão e adaptação, mas rígido de qualquer maneira. Os Samurai são guardiões de uma moral estabelecida por convenções, uma espécie de religião estabelecida por comum acordo. O princípio é que, havendo muitos dispositivos sociais, é necessário que haja uma agência de controle, constituída pela classe dos Samurai. Qualquer pessoa, homem ou mulher, pode se voluntariar para ser um Samurai, tendo, então, que seguir as regras e garantir que a ordem social seja mantida. A sociedade, assim, é regulada por tal classe, com regras que não funcionam perfeitamente, mas estão em um constante processo de melhoria. O narrador é um entusiasta dessa ideia, acredita que a moral dos Samurai é adequada, e que os benefícios são vantajosos; seu colega, entretanto, a detesta (WELLS, 1905).

Berneri critica essa utopia de Wells, dizendo que a concepção de liberdade acaba sendo muito restrita: há muitas leis, baseadas no princípio de que é com proibições que se garante a liberdade. Isso gera um resultado comum às utopias criticadas pelo próprio Wells, o de que os interesses individuais precisam ser equacionados aos interesses do Estado. Segundo Berneri, o código moral dos Samurai garante essa equação, de forma que tal classe é privilegiada, embora não tenha liberdade de estilo de vida (BERNERI, 1950).

É possível notar diversos aspectos em comum entre a utopia moderna de Wells e a concepção de mundo científica defendida 
por Neurath. ${ }^{10}$ Podemos destacar, em primeiro lugar, a ideia de que sempre haverá problemas, mas a ciência é o caminho para a superação de tais problemas e para a melhoria das condições de vida; e tal ciência não é feita em segredo de Estado, como a de Bacon, mas em um ambiente de ampla comunicação e divulgação. Em segundo lugar, nada está pronto e acabado na utopia de Wells, da mesma forma que nada foi construído a partir do zero, já que o narrador e seu colega não puderam se despir de seus próprios preconceitos; eles seguiram navegando em mar aberto, da mesma forma que os Samurai não possuem um código moral correto por princípio, sempre tendo que reconstruí-lo. A utopia moderna é elaborada em amplo debate - entre o narrador e seu colega, o apóstolo da natureza, os Samurai, e a tradição da literatura utópica. Wells diz, no final, que sua utopia não é a última e nem pode ser a única ou a utopia final (WELLS, 1905). Notamos, assim, que Wells não apresenta soluções universalmente adequadas, as quais Neurath condenaria. Berneri aponta que essa é a melhor característica de A Modern Utopia e também a mais marcante, por formatar as utopias que vieram depois (BERNERI, 1950).

Em 1923, Wells publicou Men Like Gods, em que algumas pessoas, caricaturas de diversos setores da sociedade inglesa, além de um francês, acabam sendo levadas para outra dimensão, o planeta chamado Utopia, como uma consequência imprevista de um experimento científico feito naquele outro mundo. Depois de alguns dias, começa uma epidemia fatal de uma doença trazida pelos terráqueos. Vemos, a partir disso, que a ciência permanece falível, como em A Modern Utopia, já que os experimentos têm consequências imprevistas e indesejáveis. A mesma história poderia ser contada de outro ponto de vista, narrando uma invasão de alienígenas que atacam um planeta pacífico com armas biológicas. Men Like Gods não apresenta caráter metalinguístico e nem discussões diretas de filosofia e crítica literária, sendo mais propriamente uma obra artística. Em tal livro, a humanidade desenvolveu capacidades telepáticas, tornando a sinceridade uma característica geral; além disso, a educação foi desenvolvida de tal maneira a tornar desnecessários os governos e as agências de controle. As pessoas vivem em uma espécie de Olimpo, daí o título do livro. Mas todo esse avanço foi obtido em um longo processo de experimentação científica: Utopia passou por um período conhecido como Era da Confusão, em que a ordem social foi bem parecida com a da Terra da época de Wells, até que houve um colapso desse sistema, com fome, guerras, doenças e desigualdade, gerando o esforço para construir um mundo melhor. A crítica social, típica do texto utópico, vem da comparação de Utopia no tempo presente com a Era da Confusão, sempre identificada com a Terra (WELLS, 1923).

\footnotetext{
10 Berneri nota que a estrutura social e econômica de $A$ Modern Utopia é similar à ordem social proposta pelo economista Theodor Hertzka, citado por Wells como uma de suas fontes (WELLS, 1905; BERNERI, 1950). Hertzka também é mencionado por Neurath ([1917], p. 243)
}

Berneri considera que o mundo apresentado em Men Like Gods é mais igualitário e livre que o de A Modern Utopia - menos marcado pelas convicções burguesas de Wells, segundo ela. Mas tal mundo veio a um custo, um longo processo de eugenia - sem violência e humilhação, Wells ressalta - que tornou a humanidade menos propensa à maldade e à corrupção, embora sujeita a doenças (BERNERI, 1950). A eugenia aparece em vários textos de Wells, como um caminho para aperfeiçoar a humanidade. Simon James nota, no entanto, que não se trata da visão comumente apresentada quando tal tema é levantado. Ele aponta que Wells é um cético quanto à ideia de que seja possível estabelecer valores universais e unânimes a respeito de características como adaptação, beleza, saúde e, mesmo, loucura. Dessa forma, a eugenia, na obra de Wells, não é uma tentativa de controlar absolutamente os processos de seleção natural e sexual, mas deve ser um esforço para planejar a maneira como a humanidade se encaixa em tal processo (JAMES, 2012). ${ }^{11}$

Um trecho interessante de Men Like Gods é quando os utopianos apresentam aos visitantes a ordem social de Utopia e, em seguida, recebem críticas: um padre terráqueo questiona a moral utopiana, revoltando-se com a ausência de laços matrimoniais; um poeta da alta sociedade inglesa ataca o fato de os utopianos terem alterado o Equilíbrio da Natureza, ao fazerem seleção artificial de certas características e espécies; um político liberal critica o fato de os utopianos não fazerem nada para evitar a degeneração que atinge as pessoas quando não estão em concorrência umas com as outras (WELLS, 1923). O utopiano não se esforça muito para responder às questões, mas seus pensamentos são acessíveis aos que estão próximos: para ele, os terráqueos estão muito sujeitos aos medos e tabus do início do controle científico sobre o mundo; inventam, então, forças irresistíveis que os impedem de obter avanços, "um poder além do seu próprio que os desculpa de seu dever". Para o utopiano, dessa forma, o padre não consegue ver o ser humano como realmente é, o poeta acredita em uma Mãe Natureza por trás das aparências e o político vê a Natureza como um exemplo a ser seguido, cujas crueldades devemos imitar. Tais pessoas estão "pregando o velho fatalismo e acreditando que é o ensinamento da ciência” (WELLS, 1923, p. 104).

É possível identificar esse trecho com a caracterização da atitude científica como aquela que rejeita profundezas insondáveis e barreiras intransponíveis. Um adepto da concepção de mundo científica evitaria propostas de que a sociedade ou a natureza tendem a alguma forma de equilíbrio ou de degeneração, assim como dogmas religiosos sobre a natureza humana: tais ideias são princípios a priori que acabam por barrar o avanço das pesquisas, do conhecimento e da capacidade humana de resolver problemas. Poderíamos encontrar alguma oposição do Círculo de Viena à 11 Sabe-se que a eugenia era um tema bastante discutido no início do século
XX. Mesmo assim, trata-se de um dos pontos mais controversos da obra de Wells (CLAEYS, 2010) 
singularidade de ideias dos utopianos de Wells, já que o grupo de Neurath defendia a pluralidade. No entanto, Wells explica que tal singularidade veio ao longo de dois ou três milênios - e, supomos, depois do surgimento da telepatia, o que facilitou a comunicação, os debates e o convencimento geral (WELLS, 1923).

No final de Men Like Gods, Wells apresenta o personagem principal como alguém para quem "o socialismo foi o evangelho de sua juventude", alguém que "participou de suas esperanças, suas dúvidas, seus amargos conflitos internos". Mas, depois, tal pessoa "viu o movimento perder doçura e reunir força na estreiteza das fórmulas marxistas. Ele viu-o sacrificar seu poder construtivo pela intensidade militante" (WELLS, 1923, p. 313). E a crítica ao marxismo continua, Wells diz que "o marxista [...] não teve visão; teve apenas uma condenação de coisas estabelecidas. Afastou todas as pessoas aptas e científicas, por meio de sua afetação pomposa do científico; assustou-os com sua ortodoxia intolerante". Wells, com seu ataque, aproxima-se de Neurath, dizendo que o marxista "tentou construir a unidade social a partir do ódio e rejeitou todas as outras forças orientadoras em favor da amargura de uma luta de classes [...]". Mas Wells, assim como Neurath, é otimista em relação ao futuro do socialismo:

mas agora, em seus dias de dúvida e exaustão, a visão estava retornando ao Socialismo, e o triste espetáculo de uma ditadura proletária deu lugar mais uma vez à Utopia, à demanda por um mundo justa e corretamente em paz, com seus recursos cultivados e explorados pelo bem comum, todos os seus cidadãos libertados não somente da servidão, mas da ignorância, e suas energias excedentes direcionadas resolutamente ao aumento do conhecimento e da beleza (WELLS, 1923, p. 314).

\section{H. G. WELLS E A FILOSOFIA DA CIÊNCIA}

Encontramos na obra de Wells uma expressão da concepção de mundo científica como aquela proposta por Neurath. As utopias que Neurath incentiva, embora sejam criações da ciência social, próximas até certo ponto das ideias de Mannheim, guardam um caráter imaginativo, literário, que Mannheim limita. Se a ciência social, como vimos em Neurath, deve criar utopias junto com as comunidades envolvidas, não podemos deixar de lado as utopias artísticas, que movimentam a imaginação de tais comunidades. Wells, por sua vez, parte da ideia de que a utopia é um gênero artístico que amplia as possibilidades de transformação social no imaginário do leitor. E essa transformação viria de uma maior penetração da ciência na sociedade (cf. JAMES, 2012). Falaremos agora um pouco sobre a ciência que aparece nos textos de Wells.

A teoria científica que mais influencia as utopias de Wells é a teoria da evolução das espécies de Darwin.Vimos que Wells declara isso em $A$ Modern Utopia e em Men Like Gods, os utopianos são uma espécie que costumava ser parecida com a humanidade, mas que evoluiu. Da mesma forma, em The Time Machine, temos que a humanidade no futuro se subdividiu em duas espécies, os Eloi, criaturas amorais que vivem de maneira bucólica na superficie da Terra, e os Morlocks, seres do subterrâneo, predadores dos da superficie (WELLS, 1895). E Wells adota a teoria da evolução também para elementos culturais, de modo que em suas utopias, coisas como a arte, a ciência e as instituições estão também sujeitas a fatores de seleção. Como indica Simon James, isso permitiria aproximar a visão de ciência de Wells àquela de Thomas Kuhn, segundo a qual o progresso da ciência por meio de revoluções seria semelhante à evolução das espécies (JAMES, 2012).'2

James aponta alguns elementos que aparecem na maioria das utopias de Wells e que permitem caracterizar o pensamento de tal autor. Podemos falar do fim da identidade nacional e do catolicismo, que Wells vê como ideias retrógradas que bloqueiam o progresso social. Os avanços no transporte e na comunicação, que já mencionamos, podem ser compreendidos como produtos do desejo por conforto. Embora Wells dedique algum tempo em seus livros à descrição de governos e economias, a principal característica de suas utopias é que a narrativa enfoca questões cotidianas, "utopias domésticas", como James chama. Dessa forma, Wells enfatiza questões de arquitetura e design; um exemplo é do interior das casas em $A$ Modern Utopia que não possui cantos, o que impede o acúmulo de poeira e facilita que robôs façam a limpeza rapidamente. Isso contribui para que não haja na sociedade utopiana uma classe inferiorizada de faxineiros. ${ }^{13}$ Outro aspecto comum à maioria das utopias de Wells é o fato de nada estar imune a críticas; ele mostra alternativas às mais diversas coisas, da largura das estradas à monogamia. E mesmo as soluções apresentadas por Wells são frequentemente criticadas e discutidas pelos personagens da narrativa, que nem sempre aprovam o que foi feito (JAMES, 2012).

A ideia central de Wells é que a sociedade, em seus mais diversos aspectos, pode e deve ser planejada. A economia, o transporte e a comunicação, questões domésticas, a eugenia, a ciência e a arte: tudo isso pode ser melhorado a partir de um planejamento central feito de maneira científica. Essa também é uma das principais bandeiras de Neurath, como vimos a partir de seus trabalhos sociais (NEURATH, 1943-45; 1930; 1920-21). A importância do planejamento social aparece particularmente nos textos de Neurath, escritos durante a primeira guerra: ele havia notado que certas ideias econômicas amplamente aceitas não funcionavam nas regiões de batalha; e, assim, seria interessante que cientistas sociais analisassem tais situações para gerar conclusões que serviriam

\footnotetext{
$12 \mathrm{Tal}$ aproximação é apenas indicada por James e merece desenvolvimento. Porém, não faremos isso neste artigo.

13 Lembremos que a sociedade da Inglaterra de Wells é marcada pela desigualdade
} entre nobres e criados, bem como entre patrões e trabalhadores da indústria. 
para os tempos de paz. Uma das observações de Neurath é que pode ser possível uma economia baseada em espécie, sem valores monetários, o que poderia conduzir a uma sociedade mais igualitária (NEURATH, 1917; NEMETH, 1982A; NEMETH; SCHMITZ; UEBEL, 2007).

Além da centralidade da educação e da ciência no planejamento social, outro aspecto comum a Neurath e Wells é a rejeição da tecnocracia. Nas utopias de Wells, apesar de os avanços sociais parecerem absurdos aos terráqueos, fica claro que tais avanços não foram introduzidos à força, mas por meio de um longo e tortuoso processo de experimentação. James aponta que em nenhuma utopia de Wells as pessoas trabalham de maneira compulsória: houve uma espécie de reconhecimento geral de que o trabalho era necessário e importante para o bem comum (JAMES, 2012).É possível notar, ainda, que Wells se opõe a noções fixas, categorias universais e soluções finais: toda utopia é também vista por alguns personagens como distopia; o objetivo é sempre garantir a liberdade, o que nem sempre dá certo.

A democracia na ciência e na política, muito prezada por Neurath, aparece em geral na obra de Wells com o constante debate de uma utopia com outra e com as utopias do passado. Em Men Like Gods, os utopianos explicam que quando alguém levanta uma objeção a algum aspecto da ordem social, tal questão passa a ser pensada e discutida pela sociedade em geral. Isso foi sendo feito até que, depois de muita luta e debate, os utopianos passaram a pensar em função do bem comum e, então, os governos não eram mais necessários; "nossa educação é nosso governo", diz um utopiano (WELLS, 1923). Em A Modern Utopia, como vimos, as normas sociais dos Samurai estão em constante processo de reconstrução; e, ainda, a ampla comunicação de relatórios científicos permite que o conhecimento seja mais democrático - tanto na construção quanto no consumo.

Mencionamos, neste texto, as distopias de Huxley e Zamyatin; tais obras mostram consequências desastrosas do planejamento científico da sociedade. Diante de Brave New World e We, o leitor pode ficar desconfiado de propostas como a que temos apresentado. Mas devemos lembrar que a ciência utilizada para a construção das sociedades nas obras de Huxley e Zamyatin não é pluralista e democrática; pelo contrário, é marcada pela imposição tecnocrática de um padrão unilateral de bem-estar, tomado pelo governo dos mundos descritos como a solução final e universalmente válida para todos os problemas (ALDRIDGE, 1984). As distopias não devem gerar desconfiança em relação aos projetos de Neurath e Wells, mas devem servir como um aviso para que pensemos em questões de filosofia da ciência ao pensarmos no mundo que queremos. A ciência pode nos ajudar, mas precisamos, antes de tudo, refletir sobre a ciência. ${ }^{14}$

\section{CONSIDERAÇÕES FINAIS}

Notamos que Neurath aproxima a ciência da arte, vislumbrando as duas atividades como originadas de um processo imaginativo, que visa informar a sociedade em direção a um planejamento para o futuro. A ciência apresenta uma diferença em relação à arte por não se limitar à criatividade e envolver coleta de dados, experimentos, análises de possibilidades de aplicação etc. (NEURATH, 1943-45). Mas no que diz respeito às utopias, o processo é parecido. Escrever uma utopia literária, com toda a pesquisa que isso envolve, é um trabalho semelhante ao de propor uma reforma social. Ou, no caso da distopia, a peça literária funciona como crítica.

A concepção de ciência defendida por Neurath é diferente daquela do marxismo de Mannheim, que procurava superar a tradição artística e é parecida com a de Wells, que aproxima ciência e arte. Procuramos mostrar em outro artigo que o processo de criação de utopias, na visão de Neurath, é semelhante à noção mais recente de elaboração de modelos científicos, por envolver a construção de uma situação na qual as leis da ciência funcionam como previsto para, a partir daquilo, tirar conclusões para intervir no mundo real. Mas Neurath não defendia que a sua concepção de ciência devesse ser a única. Como vimos, ele enfatiza que a ciência é como um mosaico, uma construção coletiva composta de peças irregulares. De fato, no texto de abertura da enciclopédia, Neurath parece convidar para participarem de tal obra os pensadores da chamada escola de Frankfurt, grupo próximo de Mannheim (DAHMS, 2005).

Utilizamos o livro A Journey Through Utopia como fio condutor para entender as utopias literárias. No final de tal livro, a autora, Marie Louise Berneri, aponta que o mundo vem mudando por meio da perseguição de utopias, mas parece que tudo vai ficando cada vez pior. Na metade do século XX, Berneri via o início da guerra fria, exilada na Inglaterra devido à perseguição sofrida por seu pai, um anarquista italiano morto na guerra civil espanhola. Será que toda utopia, quando aplicada, acaba se transformando em uma distopia? Berneri se mantém otimista, ela acredita que a culpa foi das utopias do passado, que eram totalitaristas, tecnocratas, restringiam liberdades e dissolviam o indivíduo no Estado. Mas isso vinha mudando, ela notava a tendência em direção às distopias e ao debate crítico, começado por H.G. Wells, e tinha a perspectiva de um público mais informado, que não aceitaria "utopias" impostas por governos, do tipo que geralmente

14 Não avançaremos nosso estudo dessas distopias no presente texto para não deixálo longo demais. 
se transforma em distopia (BERNERI, 1950).

Berneri, assim, critica a pretensão de chegar a uma utopia perfeita e universalmente válida, que forneceria soluções finais aos problemas. Ela não menciona Neurath, mas tendo partido de ideais políticos e de uma literatura em comum, não é estranho que os dois tenham chegado a pontos de vista semelhantes. Berneri encerra seu livro com uma canção tradicional americana, Big Rock Candy Mountains. ${ }^{15}$ Trata-se da utopia de um andarilho, que se dirige a uma terra distante, justa e brilhante, onde, entre outras maravilhas, o inventor do trabalho foi enforcado, esmolas crescem em arbustos, cigarros dão em árvores e é fácil fugir das prisões, cujas grades são feitas de estanho e cujos guardas têm pernas de pau. Nas Big Rock Candy Mountains, o clima é agradável, nunca chove, venta ou neva, há fontes de limonada e um lago de whiskey, há galinhas que botam ovos cozidos e pode-se dormir o dia todo. Embora essa utopia seja diferente da maior parte das comunidades ideais imaginadas pelos intelectuais, devemos notar que há uma grande quantidade de pessoas que consideraria Big Rock Candy Mountains o mundo perfeito e isso deveria ser levado em conta na tecnologia social (BERNERI, 1950).

É essa proposta de uma ciência pluralista e democrática apreendida de Neurath que gostaríamos de apresentar. Retomar as utopias na ciência social, recuperar o aspecto imaginativo para melhorar a sociedade, é um caminho interessante para atingir esse pluralismo democrático. Ao aproximar a ciência social da literatura utópica, talvez seja possível introduzir na ciência algumas características da arte, como a própria pluralidade: com isso, mais pessoas poderão usufruir dos produtos da ciência social, da mesma forma que tantas pessoas se identificam com as diferentes formas de arte.

\footnotetext{
15 A composição é anônima e a primeira gravação é de Harry McClintock (1928).
} 


\section{REFÊRENCIAS}

ALDRIDGE, A. The scientific world view in dystopia. Ann Arbor: UMI, 1984.

BACON, F. Nova Atlantis. In: BACON, F.; CAMPANELLA, T. The New Atlantis and the City of the Sun. New York: Dover, 2003 [1627]. p. 1-40

BERNERI, M.L. A journey through Utopia. New York: Schocken, 1971 [1950].

CARTWRIGHT, N. et al. Otto Neurath: philosophy between science and politics. Cambridge: Cambridge University Press, 1996.

CLAEYS, G. The origins of dystopia: Wells, Huxley and Orwell In: CLAEYS, G. (Ed.). The Cambridge Companion to Utopian Literature. Cambridge: Cambridge University Press, 2010. p. 107-31.

CARTWRIGHT, N.; CAT, J.; FLECK, L.; UEBEL, T. Otto Neurath: philosophy between science and politics. Cambridge: Cambridge University Press, 1996.

CUNHA, I.F.The Utopia of unified science: the political struggle of Otto Neurath and the Vienna Circle. Principia, v. 17, n. 2, p. 319-29, 2013.

DAHMS, H.J. Die 'Encyclopedia of Unified Science' (IEUS) Ihre vorgeschichte und ihre bedeutung fur den logischen Empirismus. In: NEMETH, E.; ROUDET, N. (Ed.). Paris-Wien. Enzyklopädien im Vergleich. Wien: Springer, 2005. p. 105-20.

DAVIS, J.C. Thomas More's Utopia: sources, legacy, and interpretation. In: CLAEYS, G. (Ed.). The Cambridge Companion to Utopian Literature. Cambridge: Cambridge University Press, 2010. p. 28-50.

ENGELS, F. Del socialismo utópico al socialismo científico. Tradução anônima. Buenos Aires: Agora, 2001 [1880].

FITTING, P. Utopia, dystopia and science fiction. In: CLAEYS, G. (Ed.). The Cambridge Companion to Utopian Literature. Cambridge: Cambridge University Press, 2010. p. 135-53.

HAHN, H.; NEURATH, O.; CARNAP, R. Wissenschaftliche Weltauffassung: der Wiener Kreis. In: NEURATH, O. Wissenschaftliche Weltauffassung, Sozialismus und logischer Empirismus. Frankfurt am Main: Suhrkamp Verlag, 1979 [1929]. p. $81-101$.
HUXLEY, A. Brave new world. New York: HarperCollins, 2006 [1932].

JAMES, S. Maps of utopia. Oxford: Oxford University Press, 2012.

KATEB, G. Utopias and Utopianism. In: SILLS, D. (Ed.). International encyclopedia of social sciences. Volume 16. London: Macmillan, 1968. p. 267-71.

MANNHEIM, K. Ideology and utopia. Tradução L. Wirth \& E. Shils. New York: Harcourt, 1985 [1936]

MARION, M. Louis Rougier, the Vienna Circle and the unity of science. In: NEMETH, E.; ROUDET, N. (Ed.). Paris-Wien. Enzyklopädien im Vergleich. Wien: Springer, 2005. p. 151-77.

MARX, K.; ENGELS, F. The communist manifesto. Tradução S. Moore \& F. Engels. London: Pluto Press, 2008 [1848]

MORE,T. Utopia. Tradução D. Baker-Smith. London: Penguin, 2012 [1516].

NEMETH, E. The Unity of Planned Economy and the Unity of Science. In: UEBEL, T. (Ed.). Rediscovering the forgotten Vienna Circle. Dordrecht: Kluwer, 1991 [1982a]. p. 275-83.

. Otto Neurath's Utopias - the will to hope. In: UEBEL,T. (Ed.). Rediscovering the forgotten Vienna Circle. Dordrecht: Kluwer, 1991 [1982b]. p. 285-92

NEMETH,E.;ROUDET,N.(Ed.). Paris-Wien.Enzyklopädien im Vergleich. Wien: Springer, 2005.

NEMETH, E.; SCHMITZ, S.; UEBEL, T. (Ed.). Otto Neurath's economics in context. Wien: Springer, 2007.

NEMETH, E.; STADLER, F. (Ed.). Encyclopedia and Utopia: the life and work of Otto Neurath. Dordrecht: Kluwer, 1996.

NEURATH, M.; COHEN, R. (Ed.). Memories of Otto Neurath. In: NEURATH, O. Empiricism and sociology. Dordrecht: Reidel, 1973. p. 1-83.

NEURATH, O. The economic order of the future and the economic sciences. In: NEURATH, O. Economic writings: selections 1904-1945. Dordrecht: Kluwer, 2004 [1917]. p. 24161 . 
. Die Utopien als gesellschaftstechnische Konstruktionen. In: NEURATH, O. Wissenschaftliche Weltauffassung, Sozialismus und logischer Empirismus. Frankfurt am Main: Suhrkamp Verlag, 1979 [1919]. p. 235-41.

Utopien. In: NEURATH, O. Gesammelte philosophische und methodologische Schriften. Wien: Hölder-Pichler-Tempsky, 1981 [1919]. p. 137-8.

A system of socialization. In: NEURATH, O. Economic writings: selections 1904-1945. Dordrecht: Kluwer, 2004 [1920-1]. p. 345-70.

Bürgerlicher marxismus. In: NEURATH, O. Gesammelte philosophische und methodologische Schriften. Wien: Hölder-Pichler-Tempsky, 1981 [1930]. p. 34956.

Unity of science as a Task. In: NEURATH, O Philosophical papers. Dordrecht: Reidel, 1983 [1935]. p. 115 20 .

Encyclopedia as 'Model'. In: NEURATH, O. Philosophical papers. Dordrecht: Reidel, 1983 [1936], p. 14558.

Unified science and its Encyclopedia. In: NEURATH, O. Philosophical papers. Dordrecht: Reidel, 1983 [1937]. p. 172-82.

Unified science as encyclopedic integration. In: NEURATH, O; CARNAP, R.; MORRIS, C. (Ed.) International encyclopedia of unified science. Volume 1. Chicago: The University of Chicago Press, 1955 [1938]. p. 1-27.

Late reflections on the theory of planning. In: NEURATH, O. Economic writings: selections 1904-1945. Dordrecht: Kluwer, 2004 [1943-45].p. 527-48.

Foundations of the social sciences. In: NEURATH, O.; CARNAP, R.; MORRIS, C. (Ed.). Foundations of the unity of science: toward an international encyclopedia of unified science. Volume 2. Chicago: The University of Chicago Press, 1970 [1944].p. 1-47.

NEURATH, O. et al. Encyclopedia and unified science. In: NEURATH, O.; CARNAP, R.; MORRIS, C. (Ed.). International encyclopedia of unified science. Volume 1. Chicago:The University of Chicago Press, 1955 [1938]. p. 1-76.

NEURATH, O.; CARNAP, R.; MORRIS, C. (Ed.). International encyclopedia of unified science. Volume 1. Chicago: The University of Chicago Press, 1955.
NEURATH, O.; CARNAP, R.; MORRIS, C. (Ed.). Foundations of the unity of science: toward an international encyclopedia of unified science. 2 Volumes. Chicago:The University of Chicago Press, 1970.

SOULEZ,A. Der Neurath-Stil, oder: derWiener Kreis, Rezeption und Rezeptionsprobleme auf den Kongressen von 1935 und 1937 in Paris. In: NEMETH, E.; ROUDET, N. (Ed.). Paris-Wien. Enzyklopädien im Vergleich. Wien: Springer, 2005. p. 121-49.

VIEIRA, F. The Concept of Utopia. In: CLAEYS, G. (Ed.). The Cambridge Companion to Utopian Literature. Cambridge: Cambridge University Press, 2010. p. 3-27.

VOSSOUGHIAN, N. Otto Neurath: the language of the global polis. Rotterdam: Nai, 2011.

WELLS, H.G. The time machine. New York: Dover, 1995 [1895].

A modern Utopia. London: Penguin, 2005 [1905].

Men like gods. Rockville: Wildside Press, 1923.

ZAMYATIN,Y. We. Tradução C. Brown. London: Penguin, 1993 [1924]. 


\title{
NEURATH AND H.G. WELLS: TOWARDS A
}

UTOPIAN SOCIAL SCIENCE

\begin{abstract}
This paper discusses the concept of utopia that appears in the works of Otto Neurath as related to the literary notion of utopia, particularly that which is found in the texts of H.G. Wells. Neurath's stance retrieves the style of the utopian socialists, which set up scientific proposals of social improvement amidst literary pieces. Neurath puts forward a social science that aims at creating utopias. This paper shows the continuity of such proposals with the ideas that appear in the works of Wells, emphasizing the notion of scientific world-conception, proposed by Neurath and the Vienna Circle, and implanted in the Unity of Science Movement. The conception of a utopian social science contributes to a scientifically educated society, able to democratically discuss the so-called improvements to which it is presented.
\end{abstract}

Keywords: Vienna Circle. Philosophy of science. Science fiction. Utopia.

\section{NEURATH Y H.G. WELLS: HACIA UNA CIENCIA SOCIAL UTÓPICA}

Resumen: En este artículo se discute el concepto de utopía en la obra de Otto Neurath en relación con la noción literaria de utopía, sustancialmente aquella encontrada en los textos de H.G. Wells. La posición de Neurath recupera el estilo de los socialistas utópicos, que hacían propuestas científicas para mejoras sociales en medio a piezas literarias. Neurath propone una ciencia social que tiene por objetivo crear utopías. Este artículo muestra la continuidad de este tipo de propuestas con las ideas que aparecen en la obra de Wells, con énfasis en la noción de la concepción científica del mundo, propuesta por Neurath y el Círculo de Viena, y que se incorporó en el Movimiento por la Unidad de la Ciencia. La concepción de una ciencia social utópica contribuye a una sociedad científicamente educada, capaz de discutir democráticamente las supuestas mejoras que se le presentan.

Palabras clave: Círculo de Viena. Filosofía de la ciencia. Ciencia ficción. 


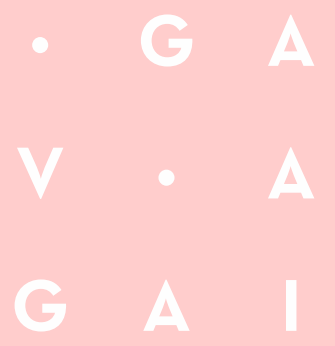

